\title{
Electromagnetic Study of MW-Class HTS Wind Turbine Generators
}

\author{
Yongchun Liang \\ School of Electrical Engineering, Hebei University of Science and Technology, Shijiazhuang, China \\ Email: lycocean@163.com
}

Received January, 2013

\begin{abstract}
High temperature superconductor (HTS) technology enables a significant reduction in the size and weight of MW-class generators for direct-drive wind turbine systems and reduce the cost of clean energy relative to conventional copper an permanent-magnet-based generators and gearbox. Using MAXWELL, we studied MW class superconducting synchronous machines. By comparison the weight, we concluded that HTS wind turbine with rotor iron is the heaviest and HTS wind turbine without rotor iron and stator teeth is the lightest. By comparison the flux density, HTS wind turbine without rotor iron is the least and HTS wind turbine without rotor iron and stator teeth is the largest. By comparison the cost, HTS wind turbine with rotor iron is the highest and the other two is almost the same. HTS wind turbine without rotor iron and stator teeth is the best type.
\end{abstract}

Keywords: FEM; High Temperature Superconductivity; Electromagnetic; Wind Turbine

\section{Introduction}

The challenges of future energy demand and the possible global warming due to fossil fuel consumption have boosted the wind turbine generator's global market. Total installed wind capacity is expected to increase to between $577 \mathrm{GW}$ and $3000 \mathrm{GW}$ by 2050[1]. In China, total installed wind capacity is expected to increase to $49 \mathrm{GW}$ by 2030[1-3].

Most present turbines are operated on-shore, but the interference with the residents and higher wind speed at sea is the motivation for building off-shore wind farms. A major fraction of the cost of off-shore farms is due to the foundations of the turbines, the grid connection and maintenance. The cost of foundations and connections can amount to $70 \%$ of the first cost. Large wind turbines would reduce this cost. Compared to the geared drive concepts, direct-drive concepts may be more attractive due to the advantages of simplified drive train and higher overall efficiency, reliability and availability by omitting the gearbox. Therefore, a break-though technology to develop light weight and compact direct-drive wind turbine generators, such as $10 \mathrm{MW}$, is surely expected in recent years. However, the generator's mass and size increase with the generator capacity. The optimum weight for a $10 \mathrm{MW}$ direct drive PM generator is greater than 300 metric tons including support structures with an air gap diameter greater than 10 meters [4-6].
To solve this problem, compact and high-power density wind turbine generators are required. High temperature superconducting technology is one of the solutions for this problem. With recent progress of fabrication technologies, 2G HTS tapes with high critical current is promising to develop high magnetic field HTS coils for power apparatuses. HTS conductors with critical current densities are as high as $200 \mathrm{~A} / \mathrm{mm}^{2}$ at $78 \mathrm{~K}$ and zero magnetic fields are now available. Whereas in conventional water-cooled windings, it is not realistic to use current densities in excess of $10 \mathrm{~A} / \mathrm{mm}^{2}$ [5]. By applying HTS to the wind turbine generators, it is expected to provide the light weight and compact design, since the magnetic field can be higher compared with the conventional generator, so that the iron core can be considerably reduced or removed $[7,8]$. Therefore, it is considered that the application of the HTS technology to the wind turbine generator is one of the key issues to break the technical power limit of the conventional wind turbine generator.

For future design of $10 \mathrm{MW}$ wind turbine system, we focus on apply high temperature superconductivity for the $1000 \mathrm{KW}$ class wind turbine generators in this study [9-12]. The electromagnetic character of three models is studied by finite element method. The first model is with iron rotor. The second model is without iron rotor. The third model is without iron rotor and stator teeth. The flux density and output power of these three models are 
discussed.

\section{Model of $1000 \mathrm{~kW}$ HTS Wind Turbine}

The electro-magnetic design of $1000 \mathrm{KW}$ wind turbine generator with HTS field windings is performed by using FEM analysis. In this study, the three-phase generator is considered. The number of the revolution is $10 \mathrm{rpm}$. In this study, we build a original type with iron rotor and calculate the flux density of the whole generator, the rotor, the stator, the air gap between rotor and stator teeth, and the armature windings. In order to reduce the weight more, we release the iron rotor and compare these two models. As an example, Figure 1(a) shows the schematic illustrations of the cross section of the wind turbine generators with the HTS field windings with iron rotor and stator teeth $[9,10]$. The model is for the case of 4-pole generator. HTS field windings are shown in Figure 1(b).

For the HTS field winding, the high magnetic field design is necessary to effectively use the advantage of HTS. DC field coils of the rotor are made of HTS tapes such as Bi-2223 or YBCO type superconductors. In this analysis, it is considered that the HTS field winding is operated at $20 \mathrm{~K}$ and the rated current density is set at $1.68 \times 108$ $\mathrm{A} / \mathrm{m}^{2}$. This value is reasonable for both HTS tapes such as $\mathrm{Bi}-2223$ or YBCO in higher magnetic field $[12,13]$. The cross section of HTS field winding is $126 \mathrm{~mm} \times$ $126 \mathrm{~mm}$. The length of HTS field winding is $1.5 \mathrm{~m}$.

In this design, the slot numbers per phase and per pole are 3 . The cross section of armature winding is $400 \mathrm{~mm} 2$. The conductor number per slot is 16 . The packing factor is 0.5 .

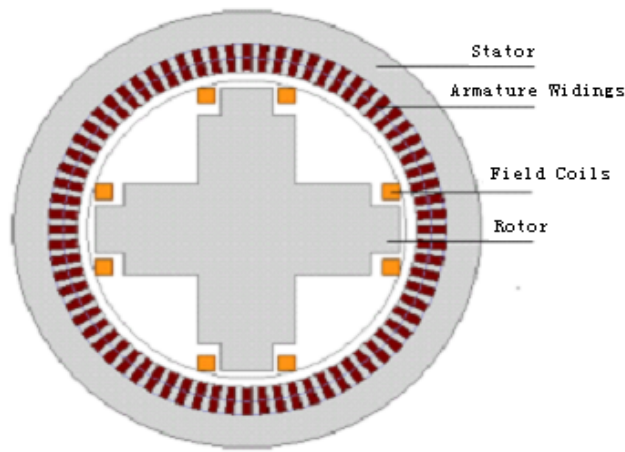

(a) Cross section

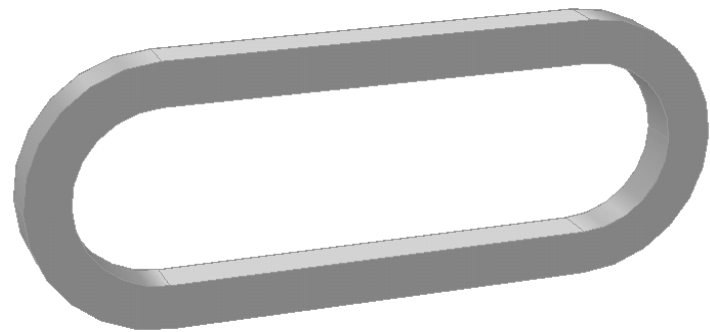

(b) Structure of HTS field coil

Figure 1. Structure of $1000 \mathrm{~kW}$ HTS wind turbine.

\section{FEM Analysis}

Finally, complete content and organizational editing before formatting. Please take note of the following items when proofreading spelling and grammar:

2D FEM is a useful tool to simulate the magnetic field of HTS turbine generator [15-18]. Figure 1 represents the FEM analysis model for the fully superconducting wind turbine generator. Because the computer is enough to simulate a full model, the full superconducting wind turbine generator is calculated. By comparison with induction generator and permanent magnet generator, the fully superconducting generator has a reduced mechanical air gap between field coils and armature windings. In this design, we assumed that an $80 \mathrm{~mm}$ air gap between field coils and armature windings. Thermal insulation layer around HTS coils is also considered.

We add $1.68 \times 10^{8} \mathrm{~A} / \mathrm{m}^{2}$ in the HTS field windings. The magnetic flux density distribution of the whole model is shown in Figure 2. The maximum magnetic flux density is about $9 \mathrm{~T}$ and located around the field windings.

Figure 3 represents the magnetic flux density distribution of the armature windings of the HTS wind generator with iron rotor. This figure refers that a maximal magnetic flux density at the armature windings was about $5 \mathrm{~T}$. The magnetic flux density under the poles is higher than other place.

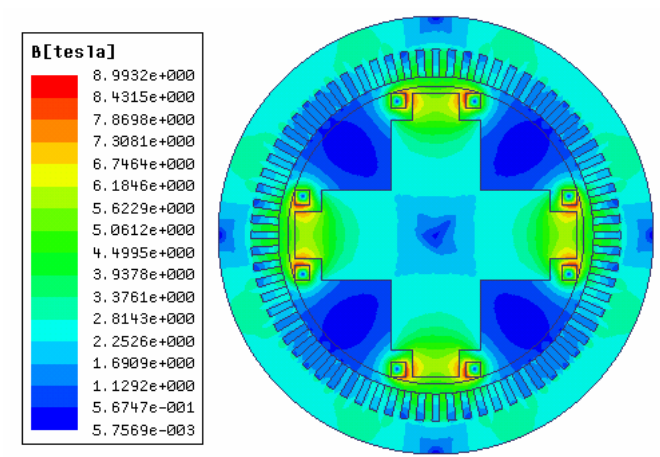

Figure 2. Magnetic field distribution of HTS turbine.

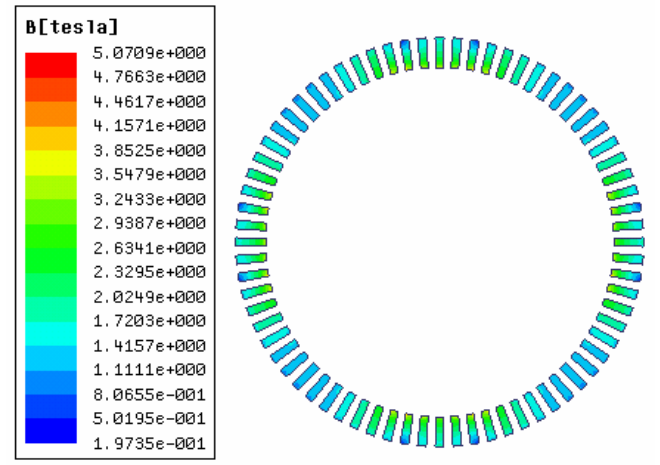

Figure 3. Magnetic field distribution of stator windings. 
Figure 4 shows the magnetic flux density distribution of the air gap of the HTS wind generator with iron rotor. The maximum magnetic flux density is about $6.6 \mathrm{~T}$ and located at around the HTS coils and the magnetic flux density in the air gap is higher than in the armature windings.

The output voltage and power is determined by the radial flux density which passes through each armature winding turn. Because the flux density distribution is uneven as shown in Figure 3, the radial flux density of each armature winding turn can be substituted by the average value. Figure 5 shows one cycle of the average radial flux density waveform of one turn of armature windings. The rms of the radial flux density of one turn of armature windings is about $1.02 \mathrm{~T}$.

Assuming that spatial distribution of the magnetic field is sinusoidal with the amplitude of $B_{0}$, the induced phase voltage (phase-to-ground) in the armature winding, $E_{0}$ is proximately expressed by

$$
E_{0}=\frac{1}{\sqrt{2}} \frac{2 \pi N_{0}}{60} r_{a} \cdot B_{0} \cdot l \cdot n_{0} \cdot q \cdot P
$$

where $N_{0}$ is the rated revolution (rpm), $r_{a}$ is the mean radius of the armature winding, $l$ is the length along the generator axis which is effective for the power conversion, $P$ is the pole number, $n_{0}$ should be an even number because of the 2-layer winding. $q$ is the slot numbers per phase and per pole.

For the model shown in Figure 1, $N_{0}=15, r_{a}=$ 1.446, $l=1.2 \mathrm{~m}, P=4, q=6$ and $n_{0}=12 . \quad B_{0}=1.02$ $\mathrm{T}$ was used. The induce phase voltage $E_{0}=565.8 \mathrm{~V}$. By assuming 3-phase balanced resistance $1.03 \Omega$, the output power is $936 \mathrm{KW}$. The output power fits the demand.

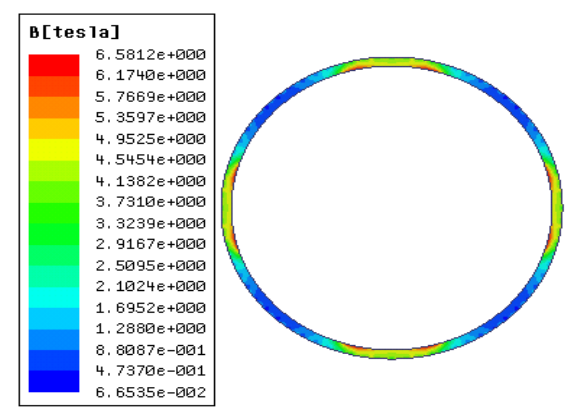

Figure 4. Magnetic field distribution of air gap.

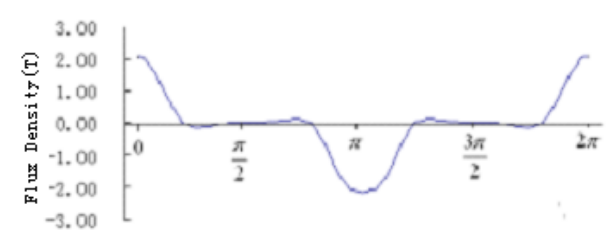

Figure 5. Radial Flux density curve of armature winding.

\section{Analysis}

In order to reduce the weight, we removed the iron rotor. The other parts are the same as the model in Figure 1. The radial magnetic flux density waveform of one turn of armature windings of HTS turbine generator without iron rotor is shown in Figure 6. The rms of the radial flux density of one turn of armature windings is about $0.8 \mathrm{~T}$. The induce phase voltage $E_{0}=443.8 \mathrm{~V}$. By assuming 3-phase balanced resistance $1.03 \Omega$, the output power is $586 \mathrm{KW}$. The output power is less than demand.

From Figures 2-4, we can know that the maximum magnetic flux density in the stator teeth is more than $2 \mathrm{~T}$ which exceeds the saturation value of the magnetic field in the conventional magnetic core material. To secure the higher magnetic field, we improve the model structure. We remove the stator teeth and the armature windings are supported in the non-magnetic material and the back yoke made of the magnetic material is used for the purpose of magnetic shield. The size is the same as the model as shown in Figure 1.

Figure 7 shows one cycle of the average radial flux density waveform of one turn of armature windings of HTS wind generator without rotor ion and stator teeth. The rms of the radial flux density of one turn of armature windings is about $1.16 \mathrm{~T}$. The induce phase voltage $E_{0}$ $=643.5 \mathrm{~V}$. By assuming 3-phase balanced resistance $1.03 \Omega$, the output power is $1232 \mathrm{KW}$. The output power fits the demand.

The model shown in Figure $\mathbf{1}$ is the heaviest model because of the iron rotor and the model without iron rotor and stator teeth is the lightest. Furthermore, the cost of

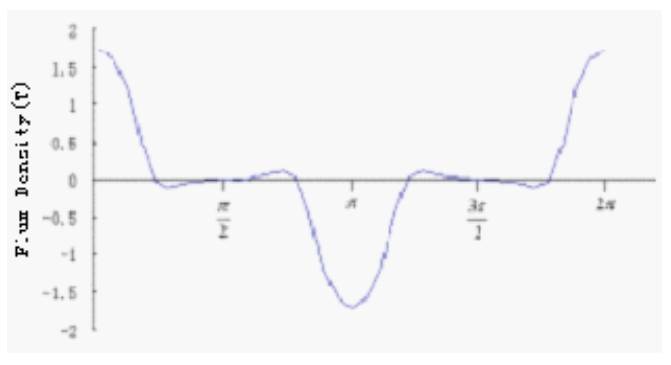

Figure 6. Radial Flux density curve of armature winding without iron rotor.

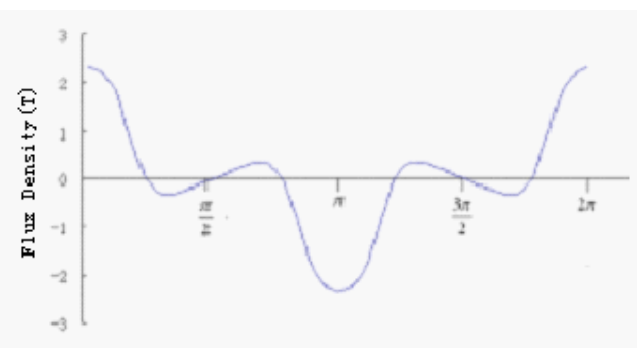

Figure 7. Radial Flux density curve of armature winding without iron rotor and stator teeth. 
the model shown in Figure 1 is the largest. By comparing the magnetic flux density, the model without iron rotor and stator teeth produce largest magnetic flux density and output largest power.

\section{Conclusions}

This paper simulated the flux density and output voltage and output power of MW class superconducting wind generator. Three kinds of generators were calculated and compared. The simulation results show that the model with iron rotor and the model without iron rotor and stator teeth can meet the output power requirement. But the HTS wind turbine generator without rotor iron and stator teeth is the lightest, the cheapest, the largest induced voltage and the largest output power. This model is the best choice.

\section{REFERENCES}

[1] A. B. Abrahamsen, N. Mijatovic, E. Seiler, et al., "Superconducting Wind Turbine Generators," Superconductor Science and Technology, Vol. 23, 2010, pp. 1-8. doi:10.1088/0953-2048/23/3/034019

[2] S. Gregory, "Progress on High Temperature Superconductor Propulsion Motors and Direct Drive Wind Generators," the 2010 International Power Electronics Conference, Sapporo, 2010.

[3] L. Clive and J. Müller, "A Direct Drive Wind Turbine HTS Generator,” IEEE Power Engineering Society General Meeting, Tampa, Florida, USA, 2007, pp. 1-8.

[4] X. T. Duan, X. Y. Zhang, J. Zhang, et al., "Finite Element Based Electromagnetic Field Simulation and Analysis of Doubly Fed Induction Generator," Power System Technology, Vol. 36, February 2012, pp. 231-236.

[5] H. Li and Z. Chen, "Overview of Difference Wind Generator Systems and Their Comparisons," IET Renewable Power Generation, Vol. 2, February 2008, pp. 123-138. doi:10.1049/iet-rpg:20070044

[6] S. He, W. Q. Wang, X. Y. Zhang, et al., "Electromagnetic Field Calculation of High Capacity Direct-Driven Permanent Magnet Synchronous Wind Power Generator Based on Finite Element Method," Power System Technology, Vol. 34, March 2010, pp. 157-161.

[7] H. Ohsaki, Y. Terao and M. Sekino, "Wind Turbine Generators using Superconducting Coils and Bulks,” Journal of Physics, Vol. 234, 2010, pp. 1-6. doi:10.1088/1742-6596/234/3/032043

[8] A. B. Abrahamsen, N. Mijatovic, E. Seiler, et al., "Design Study of $10 \mathrm{~kW}$ Superconducting Generator for Wind Turbine Applications," IEEE Transactions on Applied Superconductivity, Vol. 19, 2009, pp. 678-1681.

\section{doi: 10.1109/TASC. 2009.2017697}

[9] K. S. Ship and J. K. Sykulski, "Feild Simulation Studies for a High Temperature Superconducting Synchronous Generator with a Coreless Rotor," IEE Proceedings of Science, Measurements and Technology, Vol. 151, pp. 414-418.

[10] M. K. Al-Mosawi, C. Beduz and Y. Yang, "Construction of a 100 kVA High Temperature Superconducting Synchronous Generator," IEEE Transactions on Applied Superconductivity, Vol. 15, 2005, pp. 2182-2185. doi:10.1109/TASC.2005.849607

[11] H. M. Wen, B. Wendell, G. Kevin, et al., "Performance Test of a $100 \mathrm{~kW}$ HTS Generator Operating at 67K-77K," IEEE Transactions on Applied Superconductivity, Vol. 9, 2009, pp. 652-1655.

[12] X. H. Li, Y. G. Zhou, L. Han, et al., "Design of a High Temperature Superconducting Generator for Wind Power Applicaton,” IEEE Transactions on Applied Superconductivity, Vol. 21, 2011, pp. 155-1158.

[13] K. F. Goddard, B. Lukasik and J. K. Sykulski, “Alternative Designs of High-Temperature Superconducting Synchronous Generators,” IEEE Transactions on Applied Superconductivity, Vol. 19, 2009, pp. 3805-3811. doi: 10.1109/TASC.2009.2031626

[14] H. M. Wen, W. Bailey, M. K. Al-Mosawi, et al., "Further Testing of an "Iron-Cored" HTS Synchronous Generator Cooled by Liquid Air," IEEE Transactions on Applied Superconductivity, Vol. 21, 2011, pp. 1163-1166. doi: 10.1109/TASC. 2010.2093487

[15] S. Hidehiko, T. Teppei, M. Takaya, et al., "Development of an Axial Flux Type PM Synchronous Motor with the Liquid Nitrogen Cooled HTS Armature Windings," IEEE Transactions on Applied Superconductivity, Vol. 17, 2007, pp.1637-1640.

[16] B. Lukasik, K. F. Goddard and J. K. Sykulski, "Finite Element Assisted Method of Estimating Equivalent Circuit Parameters for a Superconducting Synchronous Generator with a Coreless Rotor," IEEE Transactions on Magnetics, Vol. 45, 2009, pp. 1226-1229. doi: 10.1109/TMAG. 2009.2012572

[17] K. S. Ship, K. F. Goddard and J. K. Sykulski, "Field Optimization in a Synchronous Generator with High Temperature Superconducting Field Winding and Magnetic Core," IEE Proceedings of Science, Measurement and Technology, Vol. 149, 2002, pp. 194-198. doi: 10.1049/ip-smt: 20020641

[18] B. Lukasik, K. F. Goddard and J. K. Sykulski, "Finite-element Assisted Method to Reduce Harmonic Content in the Air-gap Flux Density of a High-temperature Superconducting Coreless Rotor Generator,” IET Science, Measurement and Technology, Vol. 12, 2008, pp. 485-492. 